OPEN ACCESS

Edited by: Lars Kaestner,

Saarland University, Germany

Reviewed by: Ingolf Bernhardt,

Saarland University, Germany

Angela Risso,

University of Udine, Italy

${ }^{*}$ Correspondence:

Heimo Mairbäur

heimo.mairbaeurl@ med.uni-heidelberg.de

Specialty section:

This article was submitted to Membrane Physiology and Membrane

Biophysics,

a section of the journa

Frontiers in Physiology

Received: 07 November 2017 Accepted: 20 March 2018

Published: 05 April 2018

Citation:

Mairbäurl H (2018) Neocytolysis: How to Get Rid of the Extra Erythrocytes Formed by Stress Erythropoiesis Upon Descent From High Altitude. Front. Physiol. 9:345. doi: 10.3389/fphys.2018.00345

\section{Neocytolysis: How to Get Rid of the Extra Erythrocytes Formed by Stress Erythropoiesis Upon Descent From High Altitude}

\author{
Heimo Mairbäurl* \\ Medical Clinic VII, Sports Medicine, Translational Lung Research Center, German Center for Lung Research, University \\ Hospital Heidelberg, Heidelberg, Germany
}

Neocytolysis is the selective destruction of those erythrocytes that had been formed during stress-erythropoiesis in hypoxia in order to increase the oxygen transport capacity of blood. Neocytolysis likely aims at decreasing this excess amount of erythrocytes and hemoglobin $(\mathrm{Hb})$ when it is not required anymore and to decrease blood viscosity. Neocytolysis seems to occur upon descent from high altitude. Similar processes seem to occur in microgravity, and are also discussed to mediate the replacement of erythrocytes containing fetal hemoglobin $(\mathrm{HbF})$ with those having adult hemoglobin $(\mathrm{HbA})$ after birth. This review will focus on hypoxia at high altitude. Hemoglobin concentration and total hemoglobin in blood increase by $20-50 \%$ depending on the altitude (i.e., the degree of hypoxia) and the duration of the sojourn. Upon return to normoxia hemoglobin concentration, hematocrit, and reticulocyte counts decrease faster than expected from inhibition of stress-erythropoiesis and normal erythrocyte destruction rates. In parallel, an increase in haptoglobin, bilirubin, and ferritin is observed, which serve as indirect markers of hemolysis and hemoglobin-breakdown. At the same time markers of progressing erythrocyte senescence appear even on reticulocytes. Unexpectedly, reticulocytes from hypoxic mice show decreased levels of the hypoxia-inducible factor HIF- $1 \alpha$ and decreased activity of the BCL2/adenovirus E1B $19 \mathrm{kDa}$ protein-interacting protein 3 (BNIP3), which results in elevated mitochondrial activity in these cells. Furthermore, hypoxia increases the expression of miR-21, which inhibits the expression of catalase and thus decreases one of the most important mechanisms protecting against oxygen free radicals in erythrocytes. This unleashes a series of events which likely explain neocytolysis, because upon re-oxygenation systemic and mitochondrial oxygen radical formation increases and causes the selective destruction of those erythrocytes having impaired anti-oxidant capacity.

Keywords: high altitude medicine, erythropoiesis, reticulocytes, hemoglobins, total hemoglobin mass, antioxidant capacity, hypoxia 


\section{INTRODUCTION}

Adjusting amount and function of erythrocytes is required in a variety of situations, the most obvious being the decrease in $\mathrm{Hb}$ after birth and the slow replacement of erythrocytes containing $\mathrm{HbF}$ with ones with $\mathrm{HbA}$ after birth (Terrenato et al., 1981). Altered blood distribution among compartments seems to induce a reduction in the total mass of erythrocytes in microgravity (Alfrey et al., 1996). Many diseases are associated with anemia by removing damaged erythrocytes (e.g., Rifkind, 1966). Although destruction likely occurs by different mechanisms, all might be classified into the non-specific term "erythrolysis." Yet another mechanism might explain the destruction of erythrocytes when highly polycythemic high altitude natives descent from high altitude (Merino, 1950). This review addresses targeted destruction of erythrocytes upon return to sea level, which lowlanders form during staying at high altitude for a limited time. Because in particular these newly formed cells seem to be removed, their destruction is called "neocytolysis" (Alfrey et al., 1997). For better understanding selectivity of destruction, biochemical characteristics, and mechanisms of cell destruction of erythrocytes formed under normal and stress conditions will be summarized.

\section{ADJUSTMENTS OF OXYGEN TRANSPORT TO HYPOXIA AT HIGH ALTITUDE}

Oxygen supply to tissues is impaired at high altitude because decreased oxygen content of inspired air resulting in a mild decrease in arterial oxygen saturation $\left(\mathrm{SaO}_{2}\right)$ at moderate altitudes $(\sim 92 \%$ at $2,500 \mathrm{~m})$ but much more pronounced at higher altitudes $(\sim 83 \%$ at $4,500 \mathrm{~m})$ because of the sigmoidal shape of the oxygen dissociation curve (Mairbäurl and Weber, 2012).

Arterial oxygen content $\left(\mathrm{CaO}_{2}\right)$ varies during a sojourn at high altitude (Rasmussen et al., 2013): $\mathrm{CaO}_{2}$ is decreased upon acute ascent to high altitude, increases slightly within a few hours because of ventilatory acclimatization and respiratory alkalosis, increases further within days because of decreased plasma volume and increased hematocrit, and increases even further within weeks to months at high altitude because stimulated erythropoiesis increases total hemoglobin ( $\mathrm{tHb}$ ) reaching even pre-altitude values (Calbet et al., 2003).

Importantly, only $\mathrm{CaO}_{2}$ gets normalized but not $\mathrm{PaO}_{2}$, which is the main driving-force for oxygen diffusion to tissues, which therefore remain to some extent oxygen-limited. This seems to be well tolerated because at some point during a long-term stay at high altitude tHb reaches a stably-elevated value (Hurtado et al., 1945; Merino, 1950; Reynafarje et al., 1959). Performance is not improved equally because of impaired $\mathrm{O}_{2}$-diffusion (Calbet et al., 2003; Bärtsch and Swenson, 2014).

Stimulation of erythropoiesis at high altitude depends on HIF-2 $\alpha$ and erythropoietin (EPO) (Haase, 2013) and adjustments of iron metabolism (Hentze et al., 2010). EPO increases rapidly upon exposure to hypoxia; the magnitude depends on the degree of hypoxia (Eckardt et al., 1989) following a semi-logarithmic function (Wenger and Kurtz, 2011). After this initial increase EPO decreases significantly to reach a steady state level that remains significantly above normoxic values, while one is still exposed to hypoxia (Wenger and Kurtz, 2011). Yet, the rate of formation of new erythrocytes stays elevated provided there is sufficient supply with iron. Iron uptake seems to peak after approximately 4 days at high altitude, reticulocytes have their highest values after approximately 7 days in hypoxia (Siri et al., 1966). This pattern of changes has been named the "EPOparadox" (Milledge and Bärtsch, 2014). It is likely caused by a shift from hematopoietic stem cells toward erythroid progenitor cells associated with up-regulation of the erythroid transcription factor GATA-1, which stimulates EPO-receptor expression ( $\mathrm{Li}$ et al., 2011), resulting in an increased EPO-sensitivity and sustained erythropoiesis even at lower EPO. EPO receptors on progenitor cells are gradually lost during differentiation, and EPO-receptor density is very low in circulating mouse erythrocytes (Mihov et al., 2009).

The rapid increase in reticulocyte count, which is commonly observed, is likely caused by increased bone marrow blood flow and immature release of red cells (Aoki and Tavassoli, 1981). These immature cells differ in properties from reticulocytes produced under stress-free conditions, similar to what has been found in thalassemia (Rivella, 2009).

At moderate altitudes 2 weeks do not result in an increase in $\mathrm{Hb}$ in athletes (Friedmann et al., 1999), and stays longer than 3 weeks seem to increase total red cell volume by $60-250 \mathrm{ml} /$ week (Sawka et al., 2000). Natives to high altitudes in the Andes have an increased total $\mathrm{Hb}$, and their blood volume in increased by approximately 20\% (Hurtado, 1964; Sánchez et al., 1970). Similar values are observed in sojourners after weeks to months at high altitude.

\section{MATURATION OF ERYTHROID PRECURSORS}

The viability of committed erythroid progenitor cells downstream of the erythroid differentiation depends on the presence of EPO by supporting survival of erythroid precursors, which stimulates proliferation (Kimura et al., 2000). This process depends on cKit and EPO-receptors on the progenitor cells (Fisher et al., 1994; Wenger and Kurtz, 2011) and other growth factors all of which cause tyrosine-phosphorylation by Janus-kinase JAK2 (Klingmüller, 1997). JAK2 phosphorylates the EPO-receptor and the signal transducer and activator of transcription 5 (STAT5), which blocks apoptosis by inhibiting the Forkhead-Box-Protein O3 (FOXO3)-dependent pro-apoptotic pathways (Wojchowski et al., 2006). There is also an inhibition of the death receptor Fas and its ligand FasL in splenic erythroid cells, which promotes survival (Koulnis et al., 2011). The BNIP3-ligand (BNIP3L; Nix) controls mitochondrial autophagy (Sandoval et al., 2008). Thus, by the action of EPO, dividing progenitor cells are not destroyed resulting in increased production of normoblasts and release of reticulocytes into circulation (Wenger and Kurtz, 2011). In addition, phosphorylation of STAT3 increases the 
expression of antioxidant enzymes such as superoxide dismutase (SOD) and glutamin-cystein antiporter xCT while at the same time decreases the expression of proteins of the mitochondrial electron transfer chain (Linher-Melville and Singh, 2017). Together these two processes protect from hypoxia-induced mitochondrial oxygen radicals (ROS) (Chandel and Schumacker, 2000), which might impair erythropoiesis. Hypoxia also causes a HIF-1 $\alpha$ and BNIP3-dependent decrease in mitochondrial activity, which further reduces ROS formation (Semenza, 2008). Therefore, during acute hypoxia, when mitochondrial adjustments have not yet been established, hypoxia likely increases mitochondrial ROS production, whereas hypoxiaadapted cells seem to produce less ROS (Chandel et al., 1997). However, there is also evidence that hypoxia might downregulate the expression of anti-oxidant enzymes such as catalase (Song et al., 2015). If this were the case, then one might speculate on a decreased anti-oxidant activity in hypoxia-adjusted cells and increased vulnerability to oxidant damage. This issue requires clarification.

\section{STRESS-ERYTHROPOIESIS}

While normal steady-state erythropoiesis produces cells at a nearly constant rate, situations of acute tissue hypoxia such as blood loss, hemolysis, and elevated erythropoietin dramatically increase the rate of erythrocyte production and the rapid appearance of newly formed cells in circulation ("stress-erythropoiesis"). Most experimental evidence comes from work on mice, whereas evidence for human equivalents is sparse. It has to be noted that the mouse model most often used is phenylhydrazineinduced lipid-peroxydation and hemolytic anemia (Jain and Subrahmanyam, 1978), a quite "un-physiological" system.

In the acutely anemic mouse some of the EPO-induced progenitors migrate to the spleen (there may also be resident, self-renewing ones), with much enhanced maturation (Paulson et al., 2011). This is based on the finding that erythroid burst forming units (BFU-E) from the spleen differ from bone marrow BFU-E in that they form larger colonies and that the only growth factor required is EPO, whereas in the bone marrow additional burst-promoting factors are required (Valtieri et al., 1989). Bone morphogenic protein-4 (BMP4), who's expression depends on HIF- $2 \alpha$ (Wu and Paulson, 2010), induces the expansion of BFU-E in the spleen to produce specialized resident stress erythroid progenitors (Paulson et al., 2011). It is interesting to note that hypoxia strongly stimulates the expansion of spleen-derived BFU-E (Perry et al., 2007). There is only indirect evidence for similarities between murine and human stress erythropoiesis. In acute anemia human stress erythropoiesis exhibits similarities to fetal erythropoiesis (Paulson et al., 2011), because a higher proportion of blood progenitor cells than typical bone marrow derived cells contains HbF. Hypoxia of cultured progenitor cells from patients with sickle cell disease and thalassemia also induces the production of $\mathrm{HbF}$ cells. A moderate increase in $\mathrm{HbF}$ containing erythrocytes has also been found in humans after a 17-day stay at altitudes above 3,100 m (Risso et al., 2012). Thus it was speculated that this type of stress progenitors resemble the spleen-derived stress BFU-Es of the mouse model.

The marrow transit time of ${ }^{59} \mathrm{Fe}$ was shortened in mice made anemic by phlebotomy, and there was an inverse relation between transit time and the degree of anemia (Hillman, 1969). Cells appear to be released immaturely indicated by larger size, increased reticulum content, iron uptake, membrane ion transporter activity, and increased density of transferrin receptors (TfR; CD71) on the plasma membrane (summary in Rhodes et al., 2016). TfR could be detected on circulating erythrocytes longer than during normal erythropoiesis. This indicates that the rate of maturation is similar in stress and normal erythropoiesis, but that maturation of circulating stress reticulocytes takes longer because of their immature release (AlHuniti et al., 2005; Rhodes et al., 2016).

\section{NEOCYTOLYSIS}

Neocytolysis is the selective destruction of the youngest population of erythrocytes in blood, just after they had left the bone marrow, and it is thought to bring an elevated erythrocyte mass (e.g., after a stay at high altitude) back to normal (Alfrey et al., 1997). It seems to occur in a variety of different situations (Alfrey et al., 1997; Harris and Epstein, 2001; Song et al., 2017). Neocytolysis appears to be caused not simply by discontinuing stress erythropoiesis but by "controlled" processes (for a recent review see Risso et al., 2014). However, indications for neocytolysis after return from high altitude hypoxia are weak.

Merino noted disappearance of polycythemia within a few days after return from high altitude and explained it by reduced erythropoiesis (Merino, 1950), which has been indicated experimentally by decreased iron incorporation in high altitude natives on traveling to low altitude (Huff et al., 1951). Also the reticulocyte number decreased. Greater "blood destruction" was indicated by increased plasma bilirubin and urobilinogen excretion (Merino, 1950).

Pace et al. based the discussion of neocytolysis (Pace et al., 1956) on a normal erythrocyte disappearance rate of 0.0083 per day (experimentally determined from the rate of removal of transfused erythrocytes; Callender et al., 1945). Erythrocyte count and $\mathrm{Hb}$ decreased at a rate of 0.011 per day upon return to sea level after an expedition to the Himalayas (Pace et al., 1956). This was interpreted to be caused by decreased rate of erythropoiesis and increased "erythrolysis," but also by restoring the decrease in plasma volume that occurs at high altitude (Siebenmann et al., 2017).

Rice et al. studied polycythemic residents of Cerre de Pasco $(4,380 \mathrm{~m})$ upon travel to sea level and found a decrease by $9 \%$ in erythrocyte mass within 3-7 days after descent, a rapid decrease in EPO, and increased bilirubin. Changes did not occur in three subjects receiving EPO upon descent (Rice et al., 2001).

Polycythemia by itself shortens erythrocyte survival (Bogdanova et al., 2007). Risso et al. (Risso et al., 2007) separated age-fractions of erythrocytes by density gradient 
centrifugation from blood of mountaineers 1 day after return from a mountaineering expedition and found that the youngest fraction had disappeared. Cells had acquired a "senescent phenotype" indicated by decreased levels of expression of the integrin associated protein (CD47), of the complement decay accelerating factor (DAF; CD55), and of protectin (membrane inhibitor of reactive lysis; CD59), which may be an indication of increased susceptibility to phagocytosis (Risso et al., 2007). However, only one time-point had been studied, and results may be flawed by the fact that the descent itself had lasted almost 1 week.

\section{Mechanisms Causing Neocytolysis}

Results on three subjects (Rice et al., 2001) suggest that the withdrawal of EPO might be responsible for the destruction of erythrocytes produced in hypoxia. It is thought that increased EPO favors the expression of CD55 and CD59 such as observed in EPO-treated patients with renal anemia (Ohi et al., 2003), which protects from destruction by macrophages, whereas EPO withdrawal decreases expression and coincides with reappearance of anemia (Ohi et al., 2003), resulting in a picture comparable to that observed with EPO-withdrawal and treatment upon descent (Trial and Rice, 2004; Risso et al., 2014). This seems to be in line with the dependency of erythrocyte destruction on EPO and EPO-receptors in polycythemia of a gain-of-function mutation of the EPO-receptor (Divoky et al., 2016).

Another line of evidence suggests a role for altered antioxidant capacity. Erythrocytes exposed to anoxia have a decreased antioxidant capacity, indicated by decreased glutathione, nicotine-adenine dinucleotide (phosphate) (GSH, $\mathrm{NADPH}$, and NADH, resp.) redox couples and reduced membrane thiols (Rogers et al., 2009). This has been explained with a re-direction of glycolytic flux toward the synthesis of 2,3-diphosphoglycerate (2,3-DPG) and binding to deoxygenated $\mathrm{Hb}$, as well as altered glycolytic activity caused by competition of binding between deoxygenated $\mathrm{Hb}$ and glycolytic enzymes to band 3 (Weber et al., 2004), which also results in decreased NADPH and GSH formation (Rogers et al., 2009). Though this mechanism might adversely affect erythrocyte survival during high altitude hypoxia, it should rapidly be reversed upon descent thus protecting mature erythrocytes from oxidative stress. Erythropoiesis in hypoxic mice results in erythrocytes with a decreased anti-oxidative capacity because of decreased expression of catalase due to elevated levels of the micro-RNA miR-21 (Song et al., 2015). Anti-oxidative enzymes are typically high in young erythrocytes and decrease rapidly with aging (Bartosz and Bartkowiak, 1981). In the mouse model hypoxia during maturation increases mitochondrial activity in erythroid precursors due to suppression of HIF- $1 \alpha$ and decreased BNIP3L. It was argued that mitochondrial ROS production would increase in normoxia and cause neocyte destruction (Song et al., 2015). This is in sharp contradiction to results showing HIF- $1 \alpha$-induced increase in mitophagy and reduction of mitochondrial mass in a variety of cell types thought to protect from increased ROS formation and cell destruction (Zhang et al., 2008) because hypoxic mitochondria produce more ROS than normoxic ones
(Chandel et al., 1998; Chandel and Schumacker, 2000; Levraut et al., 2003). This issue awaits clarification.

Interestingly, it was found that treating mice with polyethylene glycol-conjugated catalase, which is not taken up by reticulocytes and mature erythrocytes, as well as treatment with the anti-oxidant $\mathrm{N}$-acety-cysteine increased reticulocyte half-life and prevented the reduction in hematocrit (Song et al., 2015). This result contradicts the above described argument for a role for elevated mitochondrial but argues for systemic elevation of ROS which damage hypoxia-derived neocytes, a mechanism similar to re-oxygenation injury known from many organs, e.g., the lung (Pak et al., 2017).

\section{DESTRUCTION OF SENESCENT ERYTHROCYTES}

The average life-span of mature erythrocytes is 100-130 days. The destruction rate amounts to approximately $1 \%$ per day. Senescent erythrocytes are removed by the reticulo-endothelial system, mainly in the spleen, where cells are tested for functionality and are sequestered "if they don't pass the test" (Rifkind, 1966). Random hemolysis of pre-senescent erythrocytes is negligible in humans but amounts to $0.5-1 \%$ per day in mice and rat (Landaw, 1988). Loss of erythrocytes is balanced by a production rate of $\sim 160 \times 10^{6}$ erythrocytes per minute in humans.

Interestingly, erythrocytes produced in hypoxic stress appear to have a shortened life span in some species, which is caused by increased random hemolysis and accelerated senescence (Fryers and Berlin, 1952). Every doubling of the erythrocyte production rate resulted in a $3.5 \%$ reduction in survival in rat (Landaw, 1988). Mechanisms seem to be intrinsic to erythrocytes, because cross-transfusion of newly formed cells into normoxic animals did not improve survival (Landaw, 1988). This is in line with reports on elevated levels of breakdown-products of heme in high altitude residents (Merino, 1950). It is further supported by an approximately $25 \%$ increase in the ${ }^{59} \mathrm{Fe}$ disappearance rate from blood in Peruvian high altitude relative to sea-level residents (Huff et al., 1951) indicating increased production due to accelerated sequestration to maintain stably elevated $\mathrm{Hb}$.

\section{CONSEQUENCES OF NEOCYTOLYSIS AND ACCELERATED SENESCENCE}

If in fact erythrocytes produced by hypoxic marrow have characteristics limiting their survival upon return to normoxia, then hemolysis will affect different age-cohorts of erythrocytes depending on the duration of the sojourn and on the altitude (Rasmussen et al., 2013). After a sojourn at moderately high altitude for a few weeks as done by athletes for continuous or intermittent altitude training with the goal of increasing oxygen transport capacity and sea-level performance (Levine and Stray-Gundersen, 1997; Stray-Gundersen and Levine, 2008), only a small fraction of newly released erythrocytes will be found in circulation (Rasmussen et al., 2013; Garvican-Lewis et al., 2016). In fact, athletes had an elevated fraction of immature 
reticulocytes with high expression of TfR after returning from training at $1,905 \mathrm{~m}$, which fell to sub-baseline values by day 9 , and returned to baseline on day 16 after the training camp (Nadarajan et al., 2010). Similarly, increased ferritin levels were found post-altitude-training (Garvican et al., 2012). These changes are consistent with neocytolysis. However, there were no or only minor changes in tHb within 1 or 2 weeks after return from training at $2,300 \mathrm{~m}$, during which total $\mathrm{Hb}$ had increased by $\sim 8 \%$ (Prommer et al., 2010; Garvican et al., 2012; Wachsmuth et al., 2013a,b), which may indicate decrease in erythrocyte mass by decreasing erythropoietic activity and by random loss, but a minor contribution of neocytolysis. In contrast, polycythemia after a stay at $5,260 \mathrm{~m}$ was reverted already within 1 week after descent indicating neocytolysis (Ryan et al., 2014). This may indicate that neocytolysis plays a minor role after a stay at moderate altitude, and that athletes performing altitude training may take advantage of a slightly increased oxygen carrying capacity at low altitudes for several weeks.

The situation is different for long-term sojourners and high altitude residents returning to low altitudes, because all their erythrocytes in circulation may have a decreased antioxidant capacity. Thus, elevated ROS will not only lyze young erythrocytes, but also random destruction might be increased and shorten erythrocyte life span. Hemolysis will progress until all erythrocytes with high altitude characteristics will be replaced by normoxic ones having increased antioxidant capacity. This process might cause a severe hemolytic strain, which might be

\section{REFERENCES}

Alfrey, C. P., Rice, L., Udden, M. M., and Driscoll, T. B. (1997). Neocytolysis: physiological down-regulator of red-cell mass. Lancet 349, 1389-1390. doi: 10.1016/S0140-6736(96)09208-2

Alfrey, C. P., Udden, M. M., Leach-Huntoon, C., Driscoll, T., and Pickett, M. H. (1996). Control of red blood cell mass in spaceflight. J. Appl. Physiol. 81, 98-104. doi: 10.1152/jappl.1996.81.1.98

Al-Huniti, N. H., Widness, J. A., Schmidt, R. L., and Veng-Pedersen, P. (2005). Pharmacodynamic analysis of changes in reticulocyte subtype distribution in phlebotomy-induced stress erythropoiesis. J. Pharmacokinet. Pharmacodyn. 32, 359-376. doi: 10.1007/s10928-005-0009-3

Aoki, M., and Tavassoli, M. (1981). Dynamics of red cell egress from bone marrow after blood letting. Br. J. Haematol. 49, 337-347. doi: 10.1111/j.1365-2141.1981.tb07235.x

Bartosz, G., and Bartkowiak, A. (1981). Aging of the erythrocyte. II. Activities of peroxide-detoxifying enzymes. Experientia 37, 722-723. doi: 10.1007/BF01967944

Bärtsch, P., and Swenson, E. R. (2014). High Altitude: Human Adaptation to Hypoxia. New York, NY: Springer.

Bogdanova, A., Mihov, D., Lutz, H., Saam, B., Gassmann, M., and Vogel, J. (2007). Enhanced erythro-phagocytosis in polycythemic mice overexpressing erythropoietin. Blood 110, 762-769. doi: 10.1182/blood-2006-12063602

Calbet, J. A., Boushel, R., Radegran, G., Sondergaard, H., Wagner, P. D., and Saltin, B. (2003). Why is $\mathrm{VO}_{2 \max }$ after altitude acclimatization still reduced despite normalization of arterial $\mathrm{O}_{2}$ content? Am. J. Physiol. 284, R304-R316. doi: 10.1152/ajpregu.00156.2002

Callender, S. T., Powell, E. O., and Witts, L. J. (1945). The life-span of the red cell in man. J. Path. Bact. 57, 129-139. doi: 10.1002/path. 1700570116 even more pronounced in polycythemic individuals with chronic mountain sickness.

\section{CONCLUSION AND PERSPECTIVES}

There are indications of destruction of erythrocytes formed during exposure to hypoxia upon return to normoxia. Mechanisms are unclear and might include withdrawal of EPO and impaired defense against increased ROS. Experiments are needed to better define the mechanisms causing the fast and selective removal of neocytes formed in situations of stress erythropoiesis and to clearly distinguish between selective destruction and random loss.

Another aspect to be clarified concerns the use of the term "neocytolysis," which implies the destruction selectively of erythrocytes formed in an acute and transient situation of stress erythropoiesis. Thus this term cannot be used to describe the destruction of a fraction of erythrocytes produced during longterm or even life-long exposure to such a stress environment such as fetal life and being an altitude native. In those situations it needs to be sorted out whether just erythrocytes newly released from the marrow are removed, or whether all circulating cells are more susceptible to random loss, and why.

\section{AUTHOR CONTRIBUTIONS}

The author confirms being the sole contributor of this work and approved it for publication.

Chandel, N., Budinger, G. R. S., Choe, S. H., and Schumacker, P. T. (1997). Cellular respiration during hypoxia. J. Biol. Chem. 272, 18808-18816. doi: $10.1074 /$ jbc.272.30.18808

Chandel, N. S., Maltepe, E., Goldwasser, E., Mathieu, C. E., Simon, M. C., and Schumacker, P. T. (1998). Mitochondrial reactive oxygen species trigger hypoxia- induced transcription. Proc. Natl. Acad. Sci. U.S.A. 95, 11715-11720. doi: $10.1073 /$ pnas.95.20.11715

Chandel, N. S., and Schumacker, P. T. (2000). Cellular oxygen sensing by mitochondria: old questions, new insight. J. Appl. Physiol. 88, 1880-1889. doi: 10.1152/jappl.2000.88.5.1880

Divoky, V., Song, J., Horvathova, M., Kralova, B., Votavova, H., Prchal, J. T., et al. (2016). Delayed hemoglobin switching and perinatal neocytolysis in mice with gain-of-function erythropoietin receptor. J. Mol. Med. 94, 597-608. doi: 10.1007/s00109-015-1375-y

Eckardt, K. U., Boutellier, U., Kurtz, A., Schopen, M., Koller, E. A., and Bauer, C. (1989). Rate of erythropoietin formation in humans in response to acute hypobaric hypoxia. J. Appl. Physiol. 66, 1785-1788. doi: 10.1152/jappl.1989.66.4.1785

Fisher, M. J., Prchal, J. F., Prchal, J. T., and D'Andrea, A. D. (1994). Antierythropoietin (EPO) receptor monoclonal antibodies distinguish EPOdependent and EPO-independent erythroid progenitors in polycythemia vera. Blood 84, 1982-1991.

Friedmann, B., Jost, J., Rating, T., Weller, E., Werle, E., Eckardt, K. U., et al. (1999). Effects of iron supplementation on total body hemoglobin during endurance training at moderate altitude. Int. J. Sports Med. 20, 78-85. doi: 10.1055/s-2007-971097

Fryers, G. R., and Berlin, N. I. (1952). Mean red cell life of rats exposed to reduced barometric pressure. Am. J. Physiol. 171, 465-470. doi: 10.1152/ajplegacy.1952.171.2.465

Garvican, L., Martin, D., Quod, M., Stephens, B., Sassi, A., and Gore, C. (2012). Time course of the hemoglobin mass response to natural altitude 
training in elite endurance cyclists. Scand. J. Med. Sci. Sports 22, 95-103. doi: 10.1111/j.1600-0838.2010.01145.x

Garvican-Lewis, L. A., Sharpe, K., and Gore, C. J. (2016). Time for a new metric for hypoxic dose? J. Appl. Physiol. 121, 352-355. doi: 10.1152/japplphysiol.00579.2015

Haase, V. H. (2013). Regulation of erythropoiesis by hypoxia-inducible factors. Blood Rev. 27, 41-53. doi: 10.1016/j.blre.2012.12.003

Harris, B. A. Jr., and Epstein, P. E. (2001). Out of thin air: the evolving enigma of erythropoietin and neocytolysis. Ann. Intern. Med. 134, 710-712. doi: 10.7326/0003-4819-134-8-200104170-00015

Hentze, M. W., Muckenthaler, M. U., Galy, B., and Camaschella, C. (2010). Two to tango: regulation of Mammalian iron metabolism. Cell 142, 24-38. doi: 10.1016/j.cell.2010.06.028

Hillman, R. S. (1969). Characteristics of marrow production and reticulocyte maturation in normal man in response to anemia. J. Clin. Invest. 48, 443-453. doi: 10.1172/JCI106001

Huff, R. L., Lawrence, J. H., Siri, W. E., Wasserman, L. R., and Hennessy, T. G. (1951). Effects of changes in altitude on hematopoietic activity. Medicine (Baltimore). 30, 197-217. doi: 10.1097/00005792-195109000-00001

Hurtado, A. (1964). "Some physiological and clinical aspectsof life at high altitudes," in Aging of the Lung, eds L. Cander and J. H. Moyer (New York, NY: Grune \& Stratton), 257.

Hurtado, A., Merino, C., and Delgado, E. (1945). Influence of anoxaemia on the hematopoietic acitvity. Arch. Intern. Med. 75, 284-323. doi: 10.1001/archinte.1945.00210290007002

Jain, S. K., and Subrahmanyam, D. (1978). On the mechanism of phenylhydrazineinduced hemolytic anemia. Biochem. Biophys. Res. Commun. 82, 1320-1324. doi: 10.1016/0006-291X(78)90332-7

Kimura, T., Sonoda, Y., Iwai, N., Satoh, M., Yamaguchi-Tsukio, M., Izui, T., et al. (2000). Proliferation and cell death of embryonic primitive erythrocytes. Exp. Hematol. 28, 635-641. doi: 10.1016/S0301-472X(00)00156-9

Klingmüller, U. (1997). The role of tyrosine phosphorylation in proliferation and maturation of erythroid progenitor cells-signals emanating from the erythropoietin receptor. Eur. J. Biochem. 249, 637-647. doi: 10.1111/j.1432-1033.1997.t01-1-00637.x

Koulnis, M., Liu, Y., Hallstrom, K., and Socolovsky, M. (2011). Negative autoregulation by Fas stabilizes adult erythropoiesis and accelerates its stress response. PLoS ONE 6:e21192. doi: 10.1371/journal.pone.0021192

Landaw, S. A. (1988). Factors that accelerate or retard red blood cell senescence. Blood Cells 14, 47-59.

Levine, B. D., and Stray-Gundersen, J. (1997). "Living high-training low": effect of moderate-altitude acclimatization with low-altitude training on performance. J. Appl. Physiol. 83, 102-112. doi: 10.1152/jappl.1997.83.1.102

Levraut, J., Iwase, H., Shao, Z. H., Vandenhoek, T. L., and Schumacker, P. T. (2003). Cell death during ischemia: relationship to mitochondrial depolarization and ROS generation. Am. J. Physiol. 284, H549-H558. doi: 10.1152/ajpheart.00708.2002

Li, P., Huang, J., Tian, H. J., Huang, Q. Y., Jiang, C. H., and Gao, Y. Q. (2011). Regulation of bone marrow hematopoietic stem cell is involved in high-altitude erythrocytosis. Exp. Hematol. 39, 37-46. doi: 10.1016/j.exphem.2010.10.006

Linher-Melville, K., and Singh, G. (2017). The complex roles of STAT3 and STAT5 in maintaining redox balance: lessons from STAT-mediated XCT expression in cancer cells. Mol. Cell. Endocrinol. 451, 40-52. doi: 10.1016/j.mce.2017.02.014

Mairbäurl, H., and Weber, R. E. (2012). Oxygen transport by hemoglobin. Compr. Physiol. 2, 1463-1489. doi: 10.1002/cphy.c080113

Merino, C. F. (1950). Studies on blood formation and destruction in the polycythemia of high altitude. Blood 5, 1-31.

Mihov, D., Vogel, J., Gassmann, M., and Bogdanova, A. (2009). Erythropoietin activates nitric oxide synthase in murine erythrocytes. Am. J. Physiol. 297, C378-C388. doi: 10.1152/ajpcell.00543.2008

Milledge, J. S., and Bärtsch, P. (2014). "Blood and haemostasis," in High Altitude: Human Adaptation to Hypoxia, eds E.R. Swenson and P. Bärtsch (New York, NY: Springer), 203-216.

Nadarajan, V. S., Ooi, C. H., Sthaneshwar, P., and Thompson, M. W. (2010). The utility of immature reticulocyte fraction as an indicator of erythropoietic response to altitude training in elite cyclists. Int. J. Lab. Hematol. 32, 82-87. doi: 10.1111/j.1751-553X.2008.01132.x
Ohi, H., Tamano, M., Sudo, S., and Okada, N. (2003). Recombinant EPO therapy increases erythrocyte expression of complement regulatory proteins. Am. J. Kidney Dis. 41, 179-185. doi: 10.1053/ajkd.2003.50002

Pace, N., Meyer, L. B., and Vaughan, B. E. (1956). Erythrolysis on return of altitude acclimatized individuals to sea level. J. Appl. Physiol. 9, 141-144. doi: 10.1152/jappl.1956.9.2.141

Pak, O., Sydykov, A., Kosanovic, D., Schermuly, R. T., Dietrich, A., Schroder, K., et al. (2017). Lung ischaemia-reperfusion injury: the role of reactive oxygen species. Adv. Exp. Med. Biol. 967, 195-225. doi: 10.1007/978-3-319-63245-2_12

Paulson, R. F., Shi, L., and Wu, D. C. (2011). Stress erythropoiesis: new signals and new stress progenitor cells. Curr. Opin. Hematol. 18, 139-145. doi: 10.1097/MOH.0b013e32834521c8

Perry, J. M., Harandi, O. F., and Paulson, R. F. (2007). BMP4, SCF, and hypoxia cooperatively regulate the expansion of murine stress erythroid progenitors. Blood 109, 4494-4502. doi: 10.1182/blood-2006-04-016154

Prommer, N., Thoma, S., Quecke, L., Gutekunst, T., Volzke, C., Wachsmuth, N., et al. (2010). Total hemoglobin mass and blood volume of elite Kenyan runners. Med. Sci. Sports Exerc. 42, 791-797. doi: 10.1249/MSS.0b013e3181badd67

Rasmussen, P., Siebenmann, C., Diaz, V., and Lundby, C. (2013). Red cell volume expansion at altitude: a meta-analysis and Monte Carlo simulation. Med. Sci. Sports Exerc. 45, 1767-1772. doi: 10.1249/MSS.0b013e31829047e5

Reynafarje, C., Lozano, R., and Valdivieso, J. (1959). The polycythemia of high altitudes: iron metabolism and related aspects. Blood 14, 433-455.

Rhodes, M. M., Koury, S. T., Kopsombut, P., Alford, C. E., Price, J. O., and Koury, M. J. (2016). Stress reticulocytes lose transferrin receptors by an extrinsic process involving spleen and macrophages. Am. J. Hematol. 91, 875-882. doi: 10.1002/ajh.24421

Rice, L., Ruiz, W., Driscoll, T., Whitley, C. E., Tapia, R., Hachey, D. L., et al. (2001). Neocytolysis on descent from altitude: a newly recognized mechanism for the control of red cell mass. Ann. Intern. Med. 134, 652-656. doi: 10.7326/0003-4819-134-8-200104170-00010

Rifkind, R. A. (1966). Destruction of injured red cells in vivo. Am. J. Med. 41, 711-723. doi: 10.1016/0002-9343(66)90032-5

Risso, A., Ciana, A., Achilli, C., Antonutto, G., and Minetti, G. (2014). Neocytolysis: none, one or many? A reappraisal and future perspectives. Front. Physiol. 5:54. doi: 10.3389/fphys.2014.00054

Risso, A., Fabbro, D., Damante, G., and Antonutto, G. (2012). Expression of fetal hemoglobin in adult humans exposed to high altitude hypoxia. Blood Cells Mol. Dis. 48, 147-153. doi: 10.1016/j.bcmd.2011.12.004

Risso, A., Turello, M., Biffoni, F., and Antonutto, G. (2007). Red blood cell senescence and neocytolysis in humans after high altitude acclimatization. Blood Cells Mol. Dis. 38, 83-92. doi: 10.1016/j.bcmd.2006.10.161

Rivella, S. (2009). Ineffective erythropoiesis and thalassemias. Curr. Opin. Hematol. 16, 187-194. doi: 10.1097/MOH.0b013e32832990a4

Rogers, S. C., Said, A., Corcuera, D., McLaughlin, D., Kell, P., and Doctor, A. (2009). Hypoxia limits antioxidant capacity in red blood cells by altering glycolytic pathway dominance. FASEB J. 23, 3159-3170. doi: 10.1096/fj.09-130666

Ryan, B. J., Wachsmuth, N. B., Schmidt, W. F., Byrnes, W. C., Julian, C. G., Lovering, A. T., et al. (2014). AltitudeOmics: rapid hemoglobin mass alterations with early acclimatization to and de-acclimatization from $5,260 \mathrm{~m}$ in healthy humans. PLoS ONE 9:e108788. doi: 10.1371/journal.pone.0108788

Sánchez, C., Merino, C., and Figallo, M. (1970). Simultaneous measurement of plasma volume and cell mass in polycythemia of high altitude. J. Appl. Physiol. 28, 775-778. doi: 10.1152/jappl.1970.28.6.775

Sandoval, H., Thiagarajan, P., Dasgupta, S. K., Schumacher, A., Prchal, J. T., Chen, M., et al. (2008). Essential role for Nix in autophagic maturation of erythroid cells. Nature 454, 232-235. doi: 10.1038/nature07006

Sawka, M. N., Convertino, V. A., Eichner, E. R., Schnieder, S. M., and Young, A. J. (2000). Blood volume: importance and adaptations to exercise training, environmental stresses, and trauma/sickness. Med. Sci. Sports Exerc. 32, 332-348. doi: 10.1097/00005768-200002000-00012

Semenza, G. L. (2008). Mitochondrial autophagy: life and breath of the cell. Autophagy. 4, 534-536. doi: 10.4161/auto.5956

Siebenmann, C., Robach, P., and Lundby, C. (2017). Regulation of blood volume in lowlanders exposed to high altitude. J. Appl. Physiol. 123, 957-966. doi: 10.1152/japplphysiol.00118.2017 
Siri, W. E., Van Dyke, D. C., Winchell, H. S., Pollycove, M., Parker, H. G., and Cleveland, A. S. (1966). Early erythropoietin, blood, and physiological responses to severe hypoxia in man. J. Appl. Physiol. 21, 73-80. doi: 10.1152 jappl.1966.21.1.73

Song, J., Sundar, K., Gangaraju, R., and Prchal, J. T. (2017). Regulation of erythropoiesis after normoxic return from chronic sustained and intermittent hypoxia. J. Appl. Physiol. 123, 1671-1675. doi: 10.1152/japplphysiol.00119.2017

Song, J., Yoon, D., Christensen, R. D., Horvathova, M., Thiagarajan, P., and Prchal, J. T. (2015). HIF-mediated increased ROS from reduced mitophagy and decreased catalase causes neocytolysis. J. Mol. Med. 93, 857-866. doi: 10.1007/s00109-015-1294-y

Stray-Gundersen, J., and Levine, B. D. (2008). Live high, train low at natural altitude. Scand. J. Med. Sci. Sports 18(Suppl. 1), 21-28. doi: 10.1111/j.1600-0838.2008.00829.x

Terrenato, L., Bertilaccio, C., Spinelli, P., and Colombo, B. (1981). The switch from haemoglobin $\mathrm{F}$ to $\mathrm{A}$ : the time course of qualitative and quantitative variations of haemoglobins after birth. Br. J. Haematol. 47, 31-41. doi: 10.1111/j.1365-2141.1981.tb02759.x

Trial, J., and Rice, L. (2004). Erythropoietin withdrawal leads to the destruction of young red cells at the endothelial-macrophage interface. Curr. Pharm. Des. 10, 183-190. doi: 10.2174/1381612043453423

Valtieri, M., Gabbianelli, M., Pelosi, E., Bassano, E., Petti, S., Russo, G., et al. (1989). Erythropoietin alone induces erythroid burst formation by human embryonic but not adult BFU-E in unicellular serum-free culture. Blood 74, 460-470.

Wachsmuth, N. B., Volzke, C., Prommer, N., Schmidt-Trucksass, A., Frese, F., Spahl, O., et al. (2013b). The effects of classic altitude training on hemoglobin mass in swimmers. Eur. J. Appl. Physiol. 113, 1199-1211. doi: $10.1007 / \mathrm{s} 00421-012-2536-0$

Wachsmuth, N., Kley, M., Spielvogel, H., Aughey, R. J., Gore, C. J., Bourdon, P. C., et al. (2013a). Changes in blood gas transport of altitude native soccer players near sea-level and sea-level native soccer players at altitude
(ISA3600). Br. J. Sports Med. 47(Suppl. 1), i93-i99. doi: 10.1136/bjsports-2013-0 92761

Weber, R. E., Voelter, W., Fago, A., Echner, H., Campanella, E., and Low, P. S. (2004). Modulation of red cell glycolysis: interactions between vertebrate hemoglobins and cytoplasmic domains of band 3 red cell membrane proteins. Am. J. Physiol. 287, R454-R464. doi: 10.1152/ajpregu.00060.2004

Wenger, R. H., and Kurtz, A. (2011). Erythropoietin. Compr. Physiol. 1, 1759-1794. doi: 10.1002/cphy.c100075

Wojchowski, D. M., Menon, M. P., Sathyanarayana, P., Fang, J., Karur, V., Houde, E., et al. (2006). Erythropoietin-dependent erythropoiesis: new insights and questions. Blood Cells Mol. Dis. 36, 232-238. doi: 10.1016/j.bcmd.2006.01.007

Wu, D. C., and Paulson, R. F. (2010). Hypoxia regulates BMP4 expression in the murine spleen during the recovery from acute anemia. PLoS ONE 5:e11303. doi: 10.1371/journal.pone.0011303

Zhang, H., Bosch-Marce, M., Shimoda, L. A., Tan, Y. S., Baek, J. H., Wesley, J. B., et al. (2008). Mitochondrial autophagy is an HIF-1-dependent adaptive metabolic response to hypoxia. J. Biol. Chem. 283, 10892-10903. doi: $10.1074 /$ jbc.M800102200

Conflict of Interest Statement: The author declares that the research was conducted in the absence of any commercial or financial relationships that could be construed as a potential conflict of interest.

The reviewer IB and handling Editor declared their shared affiliation.

Copyright (c) 2018 Mairbäurl. This is an open-access article distributed under the terms of the Creative Commons Attribution License (CC BY). The use, distribution or reproduction in other forums is permitted, provided the original author(s) and the copyright owner are credited and that the original publication in this journal is cited, in accordance with accepted academic practice. No use, distribution or reproduction is permitted which does not comply with these terms. 